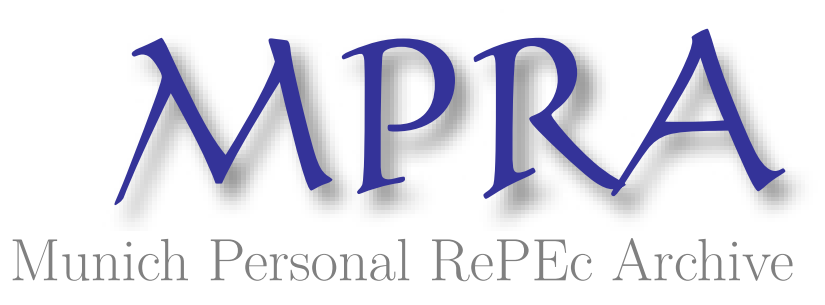

\title{
Consumption Externalities and Pigouvian Ranking - A Generalized Cobb-Douglas Example
}

\author{
Wendner, Ronald \\ University of Graz
}

2008

Online at https://mpra.ub.uni-muenchen.de/8540/

MPRA Paper No. 8540, posted 01 May 2008 09:17 UTC 


\title{
Consumption Externalities and Pigouvian Ranking A Generalized Cobb-Douglas Example*
}

\author{
Ronald Wendner \\ Department of Economics, Graz University, Austria
}

April 30, 2008

\begin{abstract}
This paper analyzes the impact of consumption externalities on the "Pigouvian ranking," according to which the second-best level of public good provision is smaller than the first-best level. Consumption externalities introduce exceptions to the Pigouvian ranking. Two necessary and sufficient conditions for reversal of the Pigouvian ranking are identified, when preferences for private goods (Cobb-Douglas) and the public good are weakly separable: (i) consumption generates a negative externality, (ii) utility is not too concave in the subutility of private goods. If preferences are strongly separable in the public good, the Pigouvian ranking is reversed if and only if the secondbest consumption price is lower than the corrective (Pigouvian) consumption price.
\end{abstract}

Keywords and Phrases: consumption externality public good provision, first-best, second-best, Pigouvian ranking.

JEL Classification Numbers: D62, H23, H41

\footnotetext{
${ }^{*}$ Financial support of the Austrian Marshall Plan Foundation is gratefully acknowledged.
} 


\section{Introduction}

This paper analyzes the impact of consumption externalities on the firstbest and second-best levels of public good provision. In particular, this work addresses the question of whether the second-best level of the public good is lower or greater than the first-best level (level issue) when consumption generates either positive or negative externalities. It is often argued that the second-best optimal level of public good provision is below the first-best level as long as the government's expenditures have to be financed by distortionary taxes ("Pigouvian ranking"), as suggested by Pigou (1947). This analysis demonstrates that consumption externalities can introduce exceptions to the Pigouvian ranking.

The importance of consumption externalities has been stressed extensively in the literature. Important references include Brekke and Howarth (2002), Easterlin (1995), Frank (1999), and Johansson-Stenman (2002, 2006), and Solnik and Hemenway (2005). It has previously been shown that consumption externalities shed important light on our understanding of issues like happiness, economic growth, asset pricing, or optimal (redistributive) taxation. With the exception of Wendner and Goulder (forthcoming), however, no paper has addressed the impact of consumption externalities on the first-best and second-best levels of public good provision. This is the focus of the present paper.

An extensive literature discusses the Pigouvian ranking, and exceptions to it. ${ }^{1}$ These papers show exceptions to the classic second-best result, where the second-best level of the public good is greater than the first-best level ("reversal of the Pigouvian ranking"). The exceptions center upon three arguments.

\footnotetext{
${ }^{1}$ Atkinson and Stern (1974), Bartolomé (2001), Batina and Ihori (2005), Chang (2000), Diamond and Mirrlees (1971), Gaube (2000, 2005), King (1986), Stiglitz and Dasgupta (1971), Wildasin (1984), Wilson (1991).
} 
First, public goods may have desirable consequences for the income distribution (King 1986, Batina 1990, Gaube 2000). Second, complementarities between the public good and a taxed private good may rise public spending beyond the first-best level (Diamond and Mirrlees 1971, Atkinson and Stern 1974, King 1986, Batina 1990). Third, a rise in public good provision implies that a larger portion of resources is transferred from the distorted private sector to the undistorted public sector (Wilson 1991b). All of these effects lower the social marginal cost of a public good, which, in turn, potentially gives rise to a reversal of the Pigouvian ranking. Sufficient conditions for such a reversal to occur are discussed in Chang (2000).

This paper identifies a further exception to the Pigouvian ranking, based on consumption externalities. In a simple economy with homogeneous households, preferences over private goods (consumption and leisure) and the public good are weakly separable. Subutility of private goods is specified by a Cobb-Douglas function, where consumption generates an externality. Within this simple "generalizes Cobb-Douglas" framework, this paper identifies two necessary and sufficient conditions for reversal of the Pigouvian ranking. First, this paper shows that the Pigouvian ranking always holds in case of a positive consumption externality. A negative consumption externality is a necessary condition for reversal of the Pigouvian ranking. In this case, a consumption tax functions both as a device for raising revenue and as an instrument for correcting the negative consumption externality. Second, reversal of the Pigouvian ranking is only possible when the utility function is not too concave in subutility of the private goods. In this case, a negative consumption externality tends to raise the marginal rate of substitution of the public for a private good. For a given rate of transformation, the Samuelson condition requires a rise of the second-best level of the public 
good (above the first-best level). As a special case, if the utility function is linear in subutility of the private goods (strong separability), the Pigouvian ranking is reversed if and only if the second-best consumption price is lower than the corrective (Pigouvian) consumption price.

With the exception of Wendner and Goulder (forthcoming), consumption externalities and the Pigouvian ranking have not been connected in the previous literature. This paper offers necessary and sufficient conditions for reversal of the Pigouvian ranking, when individual consumption generates an externality. Wendner and Goulder (forthcoming) demonstrate that Pigouvian reversal occurs whenever (i) the marginal excess burden of a consumption tax is negative, or the second-best consumption price falls short of the corrective (Pigouvian) one. However, they only consider a strongly separable utility function, and they only consider a negative consumption externality. The present analysis partially extends the analysis of Wendner and Goulder (forthcoming) to more general preferences. $^{2}$ In a CES (Cobb-Douglas) framework without externalities, Wilson (1991a) demonstrates that a reversal of the Pigouvian ranking is not possible when preferences for the private good can be represented by a CES utility function, and the ad valorem tax does not exceed $100 \%$. Here, we show that such a reversal is possible in the presence of a negative consumption externality.

Section 2 of this paper defines the representative consumer economy. Section 3 derives and discusses the first order conditions for socially optimal, first-best, and second-best allocations. Section 4 considers the impact of consumption externalities on the first-best and second-best levels of public good provision. All results of the analysis are stated in Section 4. Section 5

\footnotetext{
${ }^{2}$ At the same time, Wendner and Goulder (forthcoming) do not restrict preferences for private goods to the class of Cobb-Douglas functions. Also, Wendner and Goulder (forthcoming) focus on the relationship between the marginal excess burden and the Pigouvian ranking. Such considerations are not covered in the present study.
} 
concludes, and proofs of two lemmas are shown in the appendix.

\section{A Representative Consumer Economy}

We consider an economy with many $(h)$ homogeneous households. A representative household has preferences over consumption, $c$, leisure, $l$, average consumption, $\bar{c}$, and a pure public good, $G$. The public good enters the household's utility function, $U$, in a weakly separable way:

$$
U=U(u(c, l, \bar{c}), G)
$$

where $U$ is increasing in $u($.$) and G$, concave, and $U_{G G}<0$. Consumption imposes an externality on other households via average consumption. If $u_{\bar{c}}>$ 0 , individual utility rises in average consumption. In this case, consumption imposes a positive network externality. ${ }^{3}$ If $u_{\bar{c}}<0$, individual consumption poses a negative externality on other households.

Keeping up with the Joneses preferences represent a specific example of (1). In this case, utility is derived from consumption, leisure, and from relative consumption, $r$ :

$$
r \equiv \frac{c}{\bar{c}},
$$

where $u_{\bar{c}}<0$. This specific negative consumption externality is discussed frequently in the literature. ${ }^{4}$

Functional Specification. Subutility function $u$ is specified as Cobb-Douglas

\footnotetext{
${ }^{3}$ Partial derivatives are denoted as follows. For some function $f($.$) and variables x, y$, $f_{x} \equiv \partial f(.) / \partial x, f_{x y} \equiv \partial^{2} f() /.(\partial x \partial y) ; u_{1} \equiv \partial u(.) / \partial c, u_{2} \equiv \partial u(.) / \partial l, u_{3} \equiv \partial u(.) / \partial \bar{c}$, $u_{c} \equiv u_{1}()+.u_{3}($.$) .$

${ }^{4}$ Prominent examples include Alpizar et al. (2005), Johansson-Stenman et al. (2002, 2006), Solnick and Hemenway (1998, 2005), Ferrer-i-Carbonell (2005), Luttmer (2005), McBride (2001).
} 
function:

$$
u(c, l, \bar{c})=w(\hat{c}, l)=\hat{c}^{\alpha} l^{1-\alpha}, \quad \hat{c} \equiv c^{1 /(1-\gamma)} \bar{c}^{-\gamma /(1-\gamma)}=c r^{\gamma /(1-\gamma)} .
$$

The strength of the consumption externality is measured by the parameter $\gamma$. If $\gamma=0$, average consumption does not enter preferences. If, however, $\gamma>0(\gamma<0)$, there is a negative (positive) consumption externality.

The interpretation of parameter $\gamma$ is illustrated for an important case: relative consumption. In this case, if $\gamma>0$, utility function (3) represents keeping up with the Joneses preferences. That is, households derive utility from relative (above-average) consumption. In particular, $\gamma$ represents the marginal degree of positionality (see Alpizar 2005, and Johansson-Stenman 2002). ${ }^{5}$ For example, if $\gamma=0.1,10 \%$ of marginal utility of consumption comes from increased relative consumption, whereas $90 \%$ stems from increased absolute consumption (holding fixed the level of relative consumption).

The production side of the economy is, summarized in a fixed-coefficients transformation function, using labor as the only input:

$$
h(y-l)-h c-G=0 .
$$

The total amount of time (labor and leisure) available to each household is denoted by $y$, and the total quantity of the consumption good produced is $C=h c$. The units of $G$ and $C$ are chosen such that the constant marginal rate of transformation of $C$ for $G$ is equal to one.

\footnotetext{
${ }^{5}$ Consider $\tilde{w}(c, l, r) \equiv w(\hat{c}, l)$. The marginal degree of positionality is given by: $\gamma=$ $(\partial \tilde{w}(.) / \partial r)(\partial r / \partial c) /[(\partial \tilde{w}(.) / \partial c)+(\partial \tilde{w}(.) / \partial r)(\partial r / \partial c)]$.
} 


\section{Centralized and Decentralized Allocations}

Here, we characterize both a social optimum and decentralized first-best and second-best equilibria. In the following section, we use this characterization to derive the relationships between consumption externalities and first-best and second-best levels of public good provision.

Social Optimum. A social planner chooses $\{c, l, G\}$ according to a symmetric utilitarian welfare function. The planner takes fully into account the externality generated by individual consumption. Since each household has the same preferences, the optimum will be described by full equality. Thus, the social planner accounts for: $\bar{c}=c$, and $\hat{c}=c$. The social welfare function becomes: $W=h U(u(c, l, c), G)$. Consumption, leisure, and public good provision are derived from:

$$
\{c, l, G\}=\arg \max _{c, l, G}\{W \mid h(y-l)-h c-G=0\} .
$$

The social optimum is characterized by the following first order conditions:

$$
\begin{aligned}
& \frac{u_{c}(c, l)}{u_{l}(c, l)}=\frac{\alpha l}{(1-\alpha) c}=1, \\
& \frac{h U_{G}(u(.), G)}{U_{u}(u(.), G) u_{l}(.)}=1=\frac{h U_{G}(u(.), G)}{U_{u}(u(.), G) u_{c}(.)},
\end{aligned}
$$

and by the resource constraint. Equation (5) requires the marginal rate of substitution of consumption for leisure to equal the marginal rate of transformation (unity). Equation (6) is the Samuelson rule for optimal public goods supply, requiring the equality between the sum (over all households) of the marginal rate of substitution of the public good for leisure and the marginal rate of transformation (unity). 
First-best solution. In a competitive equilibrium, firms maximize profits subject to the production constraint (4) and prices. The wage rate (numeraire) is set equal to one. ${ }^{6}$ Let $\left(p, p_{G}\right)$ be the producer prices of $C$ and $G$ measured in labor units. The only price system that is compatible with competitive, cost minimizing producer prices is: $p=1, p_{G}=1$, where the producer prices equal the marginal costs.

In the first-best case, the government can implement lump-sum taxes $t$ (lump-sum transfers, if $t<0$ ), and a consumption tax $\tau$. The consumer price of the private good, in terms of labor units, is $q=1+\tau$. Then, a household's budget constraint is $y-t-q c-l=0$. As the public good enters the utility function $U$ in a weakly way, the Marshallian demands of $c$ and $l$ are independent of $G$. In this case, the optimization problem can be decomposed into two separate maximization problems, a household's problem, and a government's problem.

With some abuse of notation, we can write $u()=.u(\hat{c}, l)$. The household's problem consists of choosing respectively $c$ and $l$ :

$$
\{c, l\} \equiv \arg \max _{c, l}\{u(\hat{c}, l) \mid y-t-q c-l=0\}
$$

The first order condition for the competitive equilibrium is:

$$
\frac{u_{\hat{c}}(\hat{c}, l)}{u_{l}(\hat{c}, l)} \hat{c}_{c}=q \text {. }
$$

As all households have the same preferences, in equilibrium, the first order condition becomes:

$$
\left.\left(\frac{u_{\hat{c}}(\hat{c}, l)}{u_{l}(\hat{c}, l)} \hat{c}_{c}\right)\right|_{\bar{c}=c}=\frac{\alpha l}{(1-\alpha) c} \frac{1}{(1-\gamma)}=q
$$

\footnotetext{
${ }^{6}$ The problem can be equivalently restated with a wage tax instead of a consumption tax. Common practice in the literature, however, is to adopt the commodity taxation model in which labor (leisure) is taken to be the numeraire. See, e.g., Atkinson and Stern (1974), Stiglitz and Dasgupta (1971), Wendner and Goulder (forthcoming).
} 
Suppose $\gamma>0(\gamma<0)$. Then, due to the consumption externality, the marginal rate of substitution of $c$ for $l$ is higher (lower) as compared to the social optimum. In case of a negative (positive) consumption externality, a household is prepared to give up more (less) leisure for one marginal unit of consumption. This result is very intuitive. Consider the case of keeping up with the Joneses preferences. In this case, $\gamma>0$, and households like above average consumption. Thus, they are prepared to give up more (than optimal) leisure for one marginal unit of consumption.

By comparing (8) with (5), the corrective (Pigouvian) tax rate becomes:

$$
\hat{\tau}=\gamma /(1-\gamma)
$$

or, equivalently, $\hat{q} \equiv 1 /(1-\gamma)$. The corrective tax rate corresponds to the marginal social damage of a household's rise in consumption. In case of a positive consumption externality, $\gamma<0$, and the corrective tax rate becomes negative, in which case $\hat{\tau}$ represents a corrective subsidy.

In the first-best, the government's problem — with a lump-sum tax available - consists of choosing $\{t, G\}$ :

$$
\{t, G\} \equiv \arg \max _{t, G}\{U(v(\hat{q}, y-t), G) \mid h t+h(\hat{q}-1) c(\hat{q}, y-t)=G\}
$$

where $v$ denotes the indirect (sub)utility function. Notice that, from the government's point of view, per capita consumption, $\bar{c}$, is no longer exogenous (and hence does not show up in the indirect utility and Marshallian demand functions in the government's problem). The resulting first order condition

$$
\frac{U_{u}\left(u(.), G^{*}\right)}{U_{G}\left(u(.), G^{*}\right)} \frac{v(\hat{q}, 1)}{h \zeta}=1, \quad \text { where } \zeta \equiv 1-(\hat{q}-1) c(\hat{q}, 1)
$$

and the government budget constraint, $h t+h(\hat{q}-1) c(\hat{q}, y-t)=G$, determine the first-best level of public good provision, $G^{*}$, and the optimal lump-sum 
$\operatorname{tax}$ (transfer), $t^{*} \cdot{ }^{7}$ If the revenue from the corrective consumption tax equals the funds required to finance the first-best level of the public good, then the lump-sum tax equals zero: $t^{*}=0$. If, however, the revenue from the corrective consumption tax is lower (higher) than the revenue required to finance the first-best level of the public good, then $t^{*}>0\left(t^{*}<0\right)$.

\section{Lemma 1 (Indirect utility and marginal utility of labor)}

$$
v_{y}(\hat{q}, y-t)=v(\hat{q}, 1)=u_{l}(c(\hat{q}, y-t), l(\hat{q}, y-t)) \zeta .
$$

The proof of Lemma 1 is given in the appendix. Lemma 1 allows for expressing first order condition (10) in a useful way, as shown below.

Second-best solution. In the second-best case, no lump-sum taxes or transfers are available. The only instrument available to the government is a consumption tax. With a consumption tax in place, the household's problem becomes:

$$
\{c, l\} \equiv \arg \max _{c, l}\{u(\hat{c}, l) \mid y-q c-l=0\} .
$$

For a given tax rate $\tau$, the first order condition describing a second-best equilibrium is:

$$
\frac{u_{\hat{c}}(\hat{c}, l)}{u_{l}(\hat{c}, l)} \hat{c}_{c}=q .
$$

Again, in equilibrium, as all households have the same preferences, the first order condition becomes:

$$
\left.\left(\frac{u_{\hat{c}}(\hat{c}, l)}{u_{l}(\hat{c}, l)} \hat{c}_{c}\right)\right|_{\bar{c}=c}=\frac{\alpha l}{(1-\alpha) c} \frac{1}{(1-\gamma)}=q .
$$

The government's problem in the second-best case consists of choosing $\{\tau, G\}$, or, equivalently $\{q, G\}$ :

$$
\{q, G\} \equiv \arg \max _{q, G}\{U(v(q, y), G) \mid h(q-1) c(q, y)=G\}
$$

\footnotetext{
${ }^{7}$ Notice that in equilibrium, $\hat{c}=c$, and $u(\hat{c}, l)=u(c, l)$ is homothetic. Thus, $v(\hat{q}, y)$ is homogeneous of degree one in $y$, and $v_{y}(\hat{q}, y)=v(\hat{q}, 1)$.
} 
Let $R(q, y)=(q-1) c(q, y)$ denote the total tax revenue, and $R_{q}(q, y)$ denote the marginal tax revenue. The resulting first order condition,

$$
\begin{aligned}
& \frac{U_{u}\left(v(q, y), G^{* *}\right)}{U_{G}\left(v(q, y), G^{* *}\right)} \frac{-v_{q}(q, y)}{h R_{q}(q, y)}=1 \\
& \text { where } R_{q}(q, y) \equiv(q-1) c_{q}(q, y)+c(q, y),
\end{aligned}
$$

together with the government budget constraint, $h(q-1) c(q, y)=G$, determine the second-best level of public good provision, $G^{* *}$, and the associated second-best consumption tax rate, $\tau$, equivalently, the second-best consumer price $q$.

\section{Lemma 2}

$$
\frac{-v_{q}(q, y)}{h R_{q}(q, y)}=\frac{u_{l}(c(q, y), l(q, y))}{h} \frac{q}{\hat{q}}
$$

Lemma 2, which is proven in the appendix, allows for re-expressing first order condition (13) in a useful way below.

\section{Externalities and Pigouvian Ranking}

In the literature, it is often claimed that - due to distortionary effects of taxation - the second-best level of public good provision is lower than the first-best level: $G^{* *}<G^{*}$. This claim is frequently called "Pigouvian ranking."

In this section, we compare the first-best and second-best levels of public good provision for an economy with consumption externalities. We show that - for the generalized Cobb-Douglas utility function — whether the Pigouvian ranking holds or not is related to whether $q>\hat{q}$ or not.

Proposition 1 If $t^{*}=0$, the first-best and second-best allocations coincide, and $G^{*}=G^{* *}$. 
Proof. Employing Lemmas 1 and 2, we can restate the two first order conditions (10) and (13):

$$
\begin{aligned}
\frac{h U_{G}\left(v\left(\hat{q}, y-t^{*}\right), G^{*}\right)}{U_{u}\left(v\left(\hat{q}, y-t^{*}\right), G^{*}\right)} & =u_{l}\left(c\left(\hat{q}, y-t^{*}\right), l\left(\hat{q}, y-t^{*}\right)\right) \\
& =u_{c}\left(c\left(\hat{q}, y-t^{*}\right), l\left(\hat{q}, y-t^{*}\right)\right) \\
\frac{h U_{G}\left(v(q, y), G^{* *}\right)}{U_{u}\left(v(q, y), G^{* *}\right)} & =u_{l}(c(q, y), l(q, y)) \frac{q}{\hat{q}}=u_{c}(c(q, y), l(q, y)) .
\end{aligned}
$$

If $t^{*}=0$ in the optimum, then $q=\hat{q}$. In this case the right hand sides of both first order conditions are equal. Thus, the left hand sides must be equal as well. As, on the left hand sides, indirect utilities are equal, it follows that $G^{*}=G^{* *} . \quad \|$

If $t^{*}=0$, demand for the public good is such that the corrective revenue equals the cost of optimal public good provision. In this case, prices and income are equal in the first-best and second-best allocations. Hence, $G^{*}=$ $G^{* *}$.

Remark. The case where $t^{*}=0$ is only possible when there is a negative consumption externality. Only if $\gamma>0$ is there a positive revenue from corrective taxation. In case of a positive consumption externality, however, consumption is to be subsidized in the first-best optimum. That is, if $\gamma<0$, the government needs funds for financing both the corrective subsidy and the public good, hence, $t^{*}>0$.

Proposition 2 Suppose $U_{u G} \geq 0$. Then, in case of a positive consumption externality, the Pigouvian ranking always holds: $G^{*}>G^{* *}$.

Proof. The proof is given in three steps.

Step 1. The first-best allocation coincides with the social optimum. Given specification (3), the first-best allocation does not depend on the externality (that is, on $\gamma$ ). In particular, the right hand side of (10') becomes 
$\alpha^{\alpha}(1-\alpha)^{1-\alpha}$. The right hand side of $\left(13^{\prime}\right)$ equals $\alpha^{\alpha}(1-\alpha)^{1-\alpha}[q / \hat{q}]^{1-\alpha}$. As $q>\hat{q}$, the right hand side of (13') exceeds the right hand side of (10'). Therefore, the left hand side of the second-best equation (13') exceeds the left hand side of the first-best equation (10').

Step 2. By assumption, $U_{u} U_{G G}-U_{G} U_{u G}<0$, and $U_{u} U_{u G}-U_{G} U_{u u} \geq 0$. As a consequence, the marginal rate of substitution $U_{G} / U_{u}($.$) is strictly declining$ in $G$ and is non-declining in $u($.$) .$

Step 3. By definition of the first-best optimum, $v\left(\hat{q}, y-t^{*}\right) \geq v(q, y)$. In order for $U_{G} / U_{u}($.$) to be smaller in first best than in second best - which is$ required, as the right hand side of (13') exceeds the right hand side of (10') - $G^{*}$ must exceed $G^{* *}$. $\|$

The interpretation of this result is straightforward. Consumption introduces a positive externality. Taxation of consumption strengthens the distortion further. In this setting, the Pigouvian ranking always holds.

In case of a negative consumption externality, the Pigouvian holds if $q>\hat{q}$, but it may fail to hold if $q<\hat{q}$.

Proposition 3 (Pigouvian Ranking) If $q>\hat{q}$, the Pigouvian ranking always holds: $G^{* *}<G^{*}$.

Proof. This proof essentially follows the one of Proposition 2. If $q>\hat{q}$, the right hand side of (13') exceeds the right hand side of (10'). Therefore, the left hand side of the second best (13') is larger than the left hand side of the first best $\left(10^{\prime}\right)$. As $v(q, y) \leq v\left(\hat{q}, y-t^{*}\right)$, the only way the left hand side of $\left(13^{\prime}\right)$ can be larger than the left hand side of $\left(10^{\prime}\right)$ is: $G^{* *}<G^{*}$.

Again, if $q>\hat{q}$, financing of the public good by distortionary taxation makes 
the second-best level of public good provision fall short of the first-best one.

Wilson (1991) shows a special case of Proposition 3: $\gamma=0$. In a CobbDouglas economy without a consumption externality, the Pigouvian ranking always holds. That is, if $q>1=\hat{q}$, then $G^{* *}<G^{*}$.

In case of a negative consumption externality, when $q<\hat{q}$, Pigouvian reversal $\left(G^{* *}>G^{*}\right)$ can possibly occur. In order to delineate all possible cases, we first introduce some additional notation. Denote the "marginal rates of substitution" in the left hand sides of (10') and (13') respectively by $\mu\left(v^{*}, G^{*}\right)$ and $\mu\left(v^{* *}, G^{* *}\right)$. Next, denote the marginal utilities of consumption in the right hand sides of $\left(10^{\prime}\right)$ and (13') respectively by $\lambda^{*}\left(\hat{q}, y-t^{*}\right)$ and $\lambda^{* *}(q, \hat{q}, y)^{8}$. Finally, define the following two differences:

$$
\begin{aligned}
& \Delta \mu\left(q, \hat{q}, y, t^{*}, G^{*}\right)=\mu\left(v^{*}, G^{*}\right)-\mu\left(v^{* *}, G^{*}\right), \\
& \Delta \lambda\left(q, \hat{q}, y, t^{*}\right)=\lambda^{*}\left(\hat{q}, y-t^{*}\right)-\lambda^{* *}(q, \hat{q}, y) .
\end{aligned}
$$

With this notation at hand ${ }^{9}$, we can formulate the results regarding Pigouvian reversal.

\section{Proposition 4 (Reversal of Pigouvian Ranking)}

Suppose $q<\hat{q}$. If $\Delta \lambda()>.\Delta \mu($.$) , then G^{*}<G^{* *}$.

Proof. If $q<\hat{q}$, then $\Delta \lambda()=.\lambda^{*}()-.\lambda^{* *}()=.\left[\alpha^{\alpha}(1-\alpha)^{1-\alpha}\right]\left[1-(q / \hat{q})^{1-\alpha}\right]>$ 0 . Therefore, first order conditions (10') and (13') require: $\mu\left(v^{*}, G^{*}\right)>$ $\mu\left(v^{* *}, G^{* *}\right)$. By definition, $v^{*}>v^{* *}$. Therefore, $\Delta \mu() \geq$.0 . If it were the case that $\Delta \lambda()=.\Delta \mu($.$) , then both (10') and (13') would be fulfilled for the$ given, common $G^{*}$. If, however, $\Delta \lambda()>.\Delta \mu(),. \mu\left(v^{* *}, G\right)$ is to be lowered (or $\mu\left(v^{*}, G\right)$ is to be raised) in order to increase $\Delta \mu($.$) to the level equal to$

\footnotetext{
${ }^{8}$ Clearly, the marginal rates of substitution of $G$ for $c$ in the first-best and second-best cases are respectively given by $\mu\left(v^{*}, G^{*}\right) / \lambda^{*}$ and $\mu\left(v^{* *}, G^{* *}\right) / \lambda^{* *}$.

${ }^{9}$ Notice that $\Delta \mu($.$) is not the difference between the left hand sides of (10') and (13'),$ while $\Delta \lambda($.$) represents the difference between the right hand sides of (10') and (13').$
} 
$\Delta \lambda($.$) . Notice that \mu($.$) is strictly declining in G$. Thus, to increase $\Delta \mu(),. G^{*}$ is to be lowered or $G^{* *}$ is to be increased, or both. In all cases, $G^{* *}>G^{*}$.

To illustrate Proposition (4), we analyze the effects of a rise in $\gamma$, holding fixed $q$. We start at an initial situation where $q=\hat{q}$, and $G^{* *}=G^{*}$. First, rewrite the Samuelson condition (13') in the following way:

$$
h \frac{U_{G}\left(v(q, y), G^{* *}\right)}{U_{u}\left(v(q, y), G^{* *}\right) u_{c}(c(q, y), l(q, y))}=\frac{\mu\left(v(q, y), G^{* *}\right)}{\lambda^{* *}(q, \hat{q}, y)}=1,
$$

which requires the (sum over all households of the) marginal rate of substitution of $G$ for $c\left(m_{G c}\right)$ to equal the marginal rate of transformation (unity). A rise in $\gamma$ has no impact on $G^{*}$, and it raises $\hat{q}$, such that $q<\hat{q}$. As a consequence, a rise in $\gamma$ lowers both $v(q, y)$, and $u_{c}(q, y)=\alpha^{\alpha}(1-\alpha)^{1-\alpha}(q / \hat{q})^{1-\alpha}$. For a given level of $G^{* *}$, these two declines have opposing effects on the marginal rate of substitution. The $m_{G c}$ rises, as $u_{c}($.$) declines. However, the$ $m_{G c}$ may decline, as $v($.$) falls (and \mu($.$) was shown to depend non-negatively$ on $v()$.$) . Whether, for a given level of G^{* *}$, the total effect on $m_{G c}$ is positive or negative depends on the respective strengths of these opposing effects. Two cases emerge.

Case 1. The impact of the marginal utility of consumption dominates. In this case, the $m_{G c}$ increases, for a given value of $G^{* *}$. The Samuelson condition (13") then requires a rise in production of the public good and a reduction in production of the consumption good. As a consequence, $G^{* *}>G^{*}$.

Two remarks are in order. First, suppose, $\gamma=0$. If $G^{* *}>0$, then $q>1$ in order to finance the public good. But then, $q>\hat{q}=1 /(1-\gamma)=1$. Therefore, without a consumption externality, $q<\hat{q}$ is not a possibility, and Pigouvian reversal cannot occur.

Second, suppose $\mu($.$) is independent of v($.$) , that is, U_{u u}=0$. In this case, 
the impact of the marginal utility of consumption always dominates, and we can state the following corollary.

Corollary 1 (Strong Separability) Suppose $U(u, G)=u()+.f(G)$, with $f_{G}(G)>0, f_{G G}(G)<0$. Then, $q<\hat{q} \Leftrightarrow G^{*}<G^{* *}$.

Proof. With strong separability, the Samuelson conditions become: $\left[h f_{G}\left(G^{* *}\right) / u_{c}^{* *}().\right]=1=\left[h f_{G}\left(G^{*}\right) / u_{c}^{*}().\right]$. It follows:

$$
\frac{h f_{G}\left(G^{* *}\right)}{\alpha^{\alpha}(1-\alpha)^{1-\alpha}(q / \hat{q})^{1-\alpha}}=\frac{h f_{G}\left(G^{*}\right)}{\alpha^{\alpha}(1-\alpha)^{1-\alpha}} \Leftrightarrow f_{G}\left(G^{* *}\right)=(q / \hat{q})^{1-\alpha} f_{G}\left(G^{*}\right) .
$$

From $q<\hat{q}$ it follows: $f_{G}\left(G^{* *}\right)<f_{G}\left(G^{*}\right) \Leftrightarrow G^{* *}>G^{*}$, where the last inequality follows from $f_{G G}(G)<0$. \|

Corollary 1 is a special case of Proposition 4. It represents a result already shown by Wendner and Goulder (forthcoming). If $U_{u G}=U_{u u}=0$, then the Pigouvian ranking is reversed if and only if $q<\hat{q}$.

Case 2. The impact of (indirect) subutility dominates. As indirect subutility declines in the second-best situation, the $m_{G c}$ decreases, for a given value of $G^{* *}$. The Samuelson condition (13") then requires a decline in the production of the public good and a rise in the production of the consumption good. As a consequence, $G^{* *}<G^{*}$. That is, the result of Case 1 - reversal of the Pigouvian ranking - does not extend to the case where $U_{u}($.$) is sufficiently sensitive with respect to a change in indirect utility, and$ we can state Corollary 2.

Corollary 2 Suppose $q<\hat{q}$. If $\Delta \lambda(.) \leq \Delta \mu($.$) , then G^{* *} \leq G^{*}$.

The corollary follows directly from Proposition 4. In order to lower $\Delta \mu($.$) ,$ either $G^{*}$ needs to be raised or $G^{* *}$ needs to be lowered, or both. In all cases, $G^{* *} \leq G^{*}$ 


\section{Conclusions}

In the literature, it is often claimed that the second-best level of public good provision is lower than the first-best level, due to distortionary effects of taxation. This claim is frequently called Pigouvian ranking.

This paper demonstrates that consumption externalities may give rise to a reversal of the Pigouvian ranking. In particular, this paper identifies two necessary and sufficient conditions for a reversal of the Pigouvian ranking to occur, in the framework of a generalized Cobb-Douglas economy with homogeneous households. First, consumption generates a negative externality. In case of a positive consumption externality, a reversal of the Pigouvian ranking cannot occur (in the employed framework). Second, the partial derivative $U_{u}(u(c, l), G)$ must be "sufficiently insensitive" with respect to changes in the subutility function $u($.$) , as made precise in Proposition 4$.

A specific case was discussed: $U_{u u}=0$. In the presence of a negative consumption externality, a reversal of the Pigouvian ranking always occurs when $q<\hat{q}$, where $\hat{q}$ and $q$ are respectively the corrective (first-best) and second-best consumption prices. This case occurs whenever the preference for the public good is low (determining $q$ ) relative to the negative consumption externality (determining $\hat{q}$ ). 


\section{Appendix}

Proof of Lemma 1. In equilibrium $(\bar{c}=c)$, observe that

$$
\begin{aligned}
v_{y}(\hat{q}, y-t) & =u_{c}(c(\hat{q}, y-t), l(\hat{q}, y-t)) c_{y}(\hat{q}, y-t) \\
& +u_{l}(c(\hat{q}, y-t), l(\hat{q}, y-t)) l_{y}(\hat{q}, y-t) \\
& =u_{l}(.) \times\left(\frac{u_{c}(.)}{u_{l}(.)} c_{y}(\hat{q}, y-t)+l_{y}(\hat{q}, y-t)\right) \\
& =u_{l}(.)\left[1 c_{y}(\hat{q}, y-t)+l_{y}(\hat{q}, y-t)\right]
\end{aligned}
$$

where the last line follows from first order conditions (5) - the marginal rate od substitution is unity in the first best. By homotheticity of the Marshallian demand functions (in equilibrium), $c_{y}(\hat{q}, y-t)=c(\hat{q}, 1)$, and $l_{y}(\hat{q}, y-t)=$ $l(\hat{q}, 1)$. Thus,

$$
\begin{aligned}
v_{y}(\hat{q}, y-t) & =u_{l}(c(\hat{q}, y-t), l(\hat{q}, y-t))[c(\hat{q}, 1)+l(\hat{q}, 1)] \\
& =u_{l}(c(\hat{q}, y-t), l(\hat{q}, y-t)) \\
& \times[c(\hat{q}, 1)+l(\hat{q}, 1)+1-(\hat{q} c(\hat{q}, 1)+l(\hat{q}, 1))] \\
& =u_{l}(c(\hat{q}, y-t), l(\hat{q}, y-t)) \zeta
\end{aligned}
$$$$
\text { where } \zeta \equiv[1-(\hat{q}-1) c(\hat{q}, 1)] . \quad \|
$$

\section{Proof of Lemma 2.}

$R_{q}(q, y)=(q-1) c_{q}(q, y)+c(q, y)=c(q, y)\left[q c_{q}(q, y) / c(q, y)+1\right]-c_{q}(q, y)$. For a Cobb-Douglas function, the price elasticity of uncompensated demand equals (minus) unity, i.e., $R_{q}(q, y)=-c_{q}(q, y)>0$. In equilibrium $(\bar{c}=c)$ :

$$
\begin{aligned}
v_{q}(q, y) & =u_{c}(c, l) c_{q}(q, y)+u_{l}(c, l) l_{q}(q, y) \\
& =u_{c}(c, l) c_{q}(q, y) \\
& =u_{l}(c, l) c_{q}(q, y) \frac{u_{c}(c, l)}{u_{l}(c, l)} \\
& =u_{l}(c, l) c_{q}(q, y) q(1-\gamma) \\
& =u_{l}(c, l) c_{q}(q, y) q / \hat{q},
\end{aligned}
$$


where the second line uses the fact that $l_{q}=0$ for a Cobb-Douglas utility function, the fourth line follows from first order condition $(12)^{10}$, and the last line makes use of the definition of the corrective consumer price (9).

$$
\frac{-v_{q}(q, y)}{h R_{q}(q, y)}=\frac{-v_{q}(q, y)}{-h c_{q}(q, y)}=\frac{u_{l}(.) c_{q}(q, y) q / \hat{q}}{h c_{q}(q, y)}=\frac{u_{l}(.) q}{h \hat{q}} . \quad \|
$$

\section{References}

[1] Alpizar, F., F. Carlsson, O. Johansson-Stenman (2005), How Much Do We Care About Absolute versus Relative Income and Consumption?, Journal of Economic Behavior \& Organization 56, 405-421.

[2] Atkinson, A.B., N.H. Stern (1974), Pigou, Taxation and Public Goods, Review of Economic Studies 41, 119-128.

[3] Bartolomé, C.A.M. (2001), Is Pigou Wrong? Can Distortionary Taxation Cause Public Spending to Exceed the Efficient Level?, mimeo, University of Boulder, Colorado.

[4] Batina, R.G., T. Ihori (2005), Public Goods. Theories and Evidence, Berlin et al.: Springer.

[5] Brekke, K.A., R.B. Howarth (2002), Status, Growth and the Environment. Goods as Symbols in Applied Welfare Economics, Cheltenham: Edward Elgar.

[6] Chang, M.C. (2000), Rules and Levels in the Provision of Public Goods: The Role of Complementarities between the Public Good and Taxed Commodities, International Tax and Public Finance 7, 83-91.

\footnotetext{
${ }^{10} u_{c} /\left.u_{l}\right|_{c=\bar{c}}=\alpha l /[(1-\alpha) c]$, which, according to (12), equals $q(1-\gamma)$.
} 
[7] Diamond, P., J. Mirrlees (1971), Optimal Taxation and Public Production I and II, American Economic Review 61, 8-27, 261-278.

[8] Easterlin, R.A. (1995), Will Raising the Incomes of All Increase the Happiness of All?, Journal of Economic Behavior $\&$ Organization 27, $35-47$.

[9] Ferrer-i-Carbonell, A. (2005), Income and Well-Being: An Empirical Analysis of the Comparison Income Effect, Journal of Public Economics 89, 997-1019.

[10] Frank, R.H. (1999), Luxury Fever. Why Money Fails to Satisfy in an Era of Excess, New York: The Free Press.

[11] Gaube, T. (2000), When Do Distortionary Taxes Reduce the Optimal Supply of Public Goods?, Journal of Public Economics 76, 151-180.

[12] Gaube, T. (2005), Financing Public Goods with Income Taxation: Provision Rules vs. Provision Level, International Tax and Public Finance 12, 319-334.

[13] Johansson-Stenman, O., F. Carlsson, D. Daruvala (2002), Measuring Future Grantparents' Preferences for Equality and Relative Standing, Economic Journal 112, 362-383.

[14] Johansson-Stenman, O., Martinsson, P. (2006), Honestly, Why are You Driving a BMW?, Journal of Economic Behavior $\&$ Organization 60, 129-146.

[15] King, M.A. (1986), A Pigouvian Rule for the Optimum Provision of Public Goods, Journal of Public Economics 30, 273-291. 
[16] Pigou, A. (1947), A Study in Public Finance (3rd edn), London: Macmillan.

[17] Luttmer, E.F.P. (2005), Neighbors as Negatives: Relative Earnings and Well-Being, Quarterly Journal of Economics 120, 963-1002.

[18] McBride, M. (2001), Relative-Income Effects on Subjective Well-Being in the Cross-Section, Journal of Economic Behavior \& Organization 45, $251-278$.

[19] Solnick, S.J., D. Hemenway (1998), Is More Always Better? A Survey on Positional Concerns, Journal of Economic Behavior \&3 Organization 37, 373-383.

[20] Solnick, S.J., D. Hemenway (2005), Are Positional Concerns Stronger in Some Domains than in Others?, American Economic Review 95, 147151.

[21] Stiglitz, J.E., P. Dasgupta (1971), Differential Taxation, Public Goods, and Economic Efficiency, Review of Eonomic Studies 38, 151-174.

[22] Wendner, R., L.H. Goulder, Status Effects, Public Goods Provision, and Excess Burden, Journal of Public Economics, forthcoming.

[23] Wildasin, D.E. (1984), On Public Good Provision with Distortionary Taxation, Economic Inquiry 22, 227-585.

[24] Wilson, J.D. (1991a), Optimal Public Good Provision and the Ramsey Tax Model, Economics Letters 35, 57-61.

[25] Wilson, J.D. (1991b), Optimal Public Good Provision with Limited Lump-Sum Taxation, American Economic Review 81, 153-166. 